\title{
Foresight in support of European research and innovation policies: The European Commission is preparing the funding of grand societal challenges
}

\author{
Jean-Claude Burgelman • Jarka Chloupková • Werner Wobbe
}

Received: 26 September 2014 / Accepted: 28 November 2014 / Published online: 10 December 2014

(C) The Author(s) 2014. This article is published with open access at Springerlink.com

\begin{abstract}
A foresight hub within the Directorate General Research and Innovation (DG RTD) of the European Commission will support the decision-making procedures of the EU Horizon 2020 research, technology, and innovation programme. Foresight in particular is seen as an instrument defining research priorities for European society's needs in support of the 'grand societal challenges'.

The new initiative marks the recent success of the institutional and administrative application of foresight and derives from a long history of approaches to foresight taken by the European Commission. In fact, the Commission has been implementing measures to both internalise and externalise foresight during various periods since the 1970s. This paper outlines the various phases and approaches of foresight at the European Commission. It contextualises the new attempt of the foresight hub that is assumed to support the next European Commission's research and innovation policies.
\end{abstract}

Keywords European Commission · Horizon 2020 .

Administrative foresight · Good governance

The authors have worked in relation to foresight activities of the European Commission over time. However, the views expressed in this article are these of the authors and might not in any circumstances be regarded as stating an official position of the European Commission. The authors are grateful to Nikos Kastrinos and Rene von Schomberg for comments on this article.

This article is part of the Topical Collection on The Future of Europe, guest-edited by Markus Pausch.

J.-C. Burgelman · J. Chloupková $(\bowtie) \cdot$ W. Wobbe

European Commission, DG Research \& Innovation, Unit A6, ORBN

10/114, 1049 Brussels, Belgium

e-mail: jarka.brussels@gmail.com

URL: http://ec.europa.eu/research

\section{Introduction}

The 2008 financial crisis and its aftermath could have triggered the acceptance and the re-appearance of foresight in the EU's policy toolbox. Thus, instruments are needed to detect early crisis phenomena and to identify sustainable ways to overcome these.

Over time in DG Research and Innovation, foresight has taken different forms in terms of approach, methodology and operation. Originally more of an academic activity, it has developed as an instrument for policy-making. However, foresight has been informative in nature, focusing on influencing policy thinking rather than policy making. ${ }^{1}$ Today, foresight is accepted as a knowledge tool for decision-making on R\&I priorities.

The article will explain firstly the approach of foresight in the context of good governance. Secondly it will outline the new institutional and administrative approach of foresight in the Commission. Thirdly it will look retrospectively at earlier approaches and phases of foresight in the European Commission. Then the article will describe the framework of the 'grand societal challenges' relevant for the operation of the foresight hub before eventually concluding its reasoning.

\section{Foresight and good governance}

As latterly understood, foresight feeds not only into thinking about and debating the future but also into shaping the future by means of a structured process. Historically, it has developed from pure technological and economic forecasting to a policy instrument involving stakeholder participation. The

\footnotetext{
${ }^{1}$ Rand Cooperation: Using foresight to improve the science-policy relationship, Luxembourg 2006.
} 
same has been observed outside the Commission. Foresight is an enlightened approach to policy-making.

In one sense, the Commission's mainstreaming of foresight is a response to the challenge of improving its administration and governance, ${ }^{2}$ as outlined in its White Paper on European Governance. ${ }^{3}$ This paper sought to involve more people and organisations in policy-making and called for more openness, accountability and responsibility. In view of the diversity of national institutions, the Commission announced that it favoured policies based on framework directives and coregulation in view of the diversity of national institutions. This was to ensure smoother implementation instead of insisting on more directives and other legislation. Consequently, the Commission moved to the 'open method of coordination', which is a 'soft power' approach to governance steered and coordinated by the Commission itself.

When it comes to new initiatives in the field of economic and social matters, the Commission seeks to lead the European policy agenda. This is achieved through documents setting out comparative information, results of Europe-wide consultations with stakeholders in the field, and options for action plans. The Member States then tend to reflect these policy agendas in their own national policies. The Commission has initiated Europe-wide debate on many policy issues. ${ }^{4}$ This debate-based approach to policy leads to new forms of cooperation between Member States and the Commission rather than directives and executive decisions.

The Commission works on consensus-building in interinstitutional fora, as well as with Member State representatives in committees and through inter-governmental cooperation in order to implement policies. One example of this approach is the 'open method of coordination', rather than using legislative power for policy implementation. This is a specific form of cooperation between Member States and the Commission based on various types of benchmarking. Under the European Semester, ${ }^{5}$ the Commission issues recommendations and carries out monitoring. Member States are

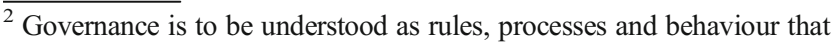
affect how power is exercised. Good governance involves transparent administrative processes and policy objectives, efficient spending, value for money and stakeholder consultation.

${ }^{3}$ http://eur-lex.europa.eu/legal-content/EN/TXT/PDF/?uri= CELEX:52001DC0428\&rid=2

${ }^{4}$ Such as the notion of competitiveness, factors that foster or hinder it, benchmarking, economic framework conditions, sustainability and best available technologies, the information and knowledge society, evaluation, the reform of higher education and, of course, the 'grand societal challenges'. For details see: http://ec.europa.eu/programmes/ horizon2020/en/news/grand-challenge-design-and-societal-impacthorizon-2020

${ }^{5}$ The 'European Semester' is the EU's cycle of economic and fiscal policy coordination. It focuses on the first half of each year (the 'semester'). Member States align their budgetary and economic policies with objectives and rules agreed at EU level; see: http://www.consilium. europa.eu/special-reports/european-semester
}

required to report on progress and implement the guidelines at national level according to their particular circumstances. This open but informed method/process is essential where governance is seen as involving a broad range of stakeholders and experts in policy-making. This has become a feature of European politics and the EU's approach to governance.

Foresight is able to significantly contribute to these peculiarly European methods of governance. Foresight procedures can help tackle innovation obstacles by mobilising a range of societal and economic stakeholders to overcome problems caused by the 'grand societal challenges'. This is through the Innovation Union initiative ${ }^{6}$ and the development of technology platforms. In that spirit, foresight contributes to the 'soft power' approach to governance. Consequently, it can contribute to good governance practices, such as information, consultation, consensus-building and enlightening policymaking.

\section{The new institutional and administrative approach of foresight}

Since 2014, foresight activities have been integral to the Commission's priority-setting in research and innovation (R\&I) policy and action. They will shape the preparation of work programmes for upcoming R\&I programmes under Horizon $2020 .^{7}$

As an integral part of the Commission's administrative culture, foresight is expected to be used as follows:

- to support the Horizon 2020 strategic programme;

- to improve interaction with stakeholders by:

- helping to develop a 'foresight' community in the EU;

- linking foresight in Member States;

- systematically integrating advisory structures into the Horizon 2020;

- creating an internal community.

After a long process of learning from various foresight activities, ${ }^{8}$ the recent foresight developments have been reintroduced to DG RTD. This time, it comes in the form of

\footnotetext{
${ }^{6}$ The Innovation Union, one of seven flagship initiatives to implement the Europe 2020 Strategy, aims to ensure that new knowledge-intensive products and services contribute substantially to growth and jobs. It is a strategic and comprehensive concept to innovation in a broad sense and as a greater political goal; see: http://ec.europa.eu/research/innovationunion/index_en.cfm or http://era.gv.at/directory/135

${ }^{7} \mathrm{http} / / / \mathrm{ec}$.europa.eu/programmes/horizon2020/

${ }^{8}$ Building foresight capacities in European academic research or using internal advisory capacity.
} 
administrative mainstreaming, whereby a systematic foresight procedure will influence decision-making on the Horizon 2020 work programme.

The European Forum on Forward Looking Activities (EFFLA), which consisted of high level expert group of 15 dedicated Members, ${ }^{9}$ was set up to ensure genuinely evidence-based and forward-looking policy-making. EFFLA drew up a specially tailored process for the Commission. This was due to enter into force in 2014.

Diagram: Suggested modus operandi of the envisaged Foresight Hub. This Modus Operandi has been inspired by a system used by Tekes, Finland.
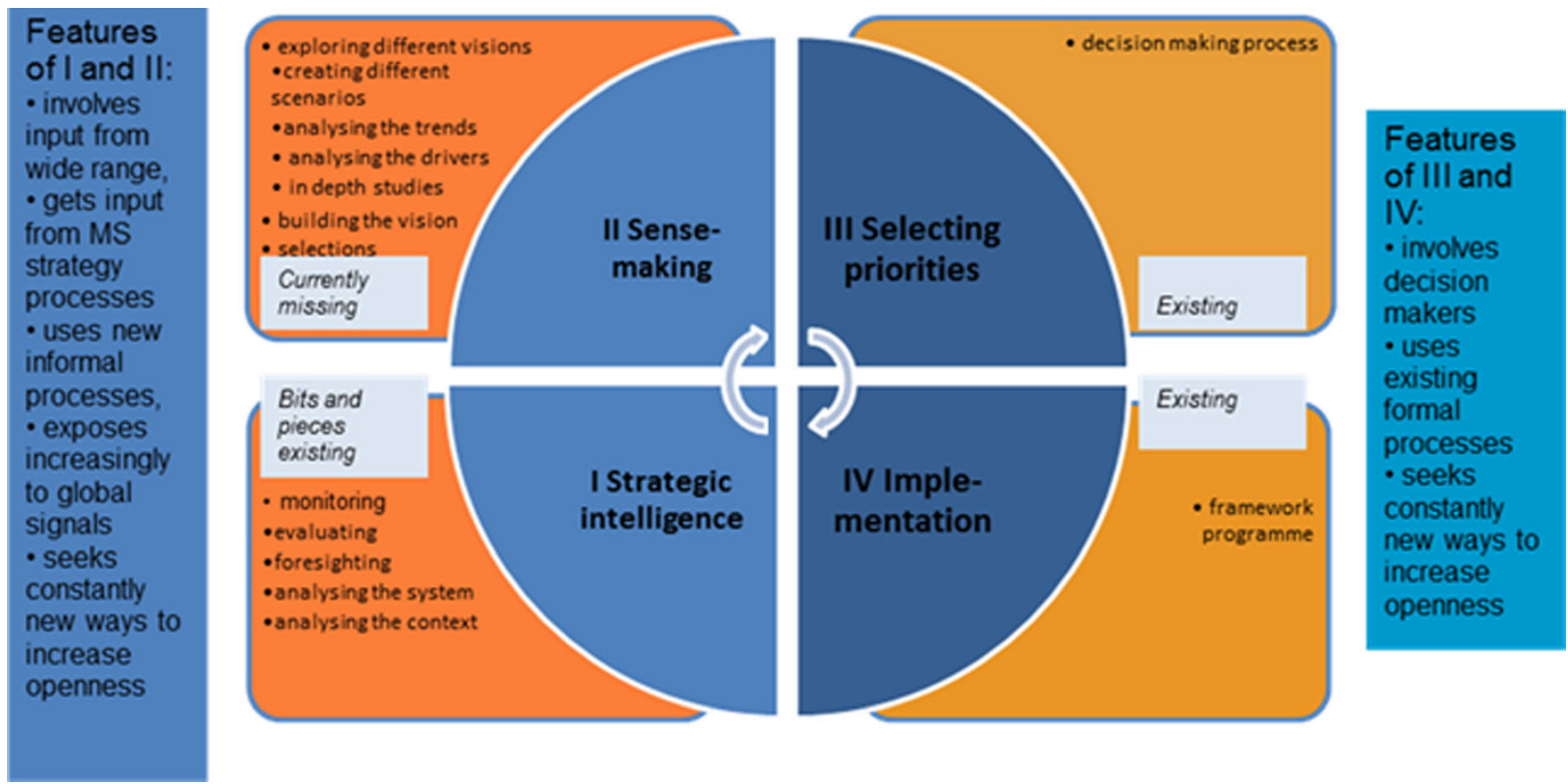

This foresight process is made up of four parts: Part I Strategic intelligence, Part II - Sense-making, Part III - Selecting priorities, and Part IV - Implementation (see diagram).

Parts I and II introduce a challenge to the Commission, as they take on board input from a wide range of sources, including Member States. In addition it takes account of any influences to be as inclusive and open as possible.

'Strategic intelligence' in a broad and comprehensive manner has until now been missing from the process of the Commission's activities and hence requires more attention. This step involves a systemic process of collecting, analysing and making sense of all strategic intelligence to gather evidence, future perspectives and options needed to make enlightened decisions on priorities and implementation.

The phase of 'sense-making' intends to reveal gaps in the input collected of the strategic intelligence. It challenges the results of intelligence reports by exploring alternatives. 'Sense-making' was part of the Commission's process before EFFLA made its recommendation, but it was a relatively weak

\footnotetext{
${ }^{9}$ Prof. Peter Piot, Mr. Dan Andree, Prof. João Caraca, Prof. Luke Georghiou, Dr. Philippe Kourilsky, Dr. Riikka Heikinheimo, Dr. Gill Ringland, Prof. Michal Kleiber, Prof. Athena Linos, Dr. Horst Soboll, Dr. Matthias Weber, Dr. Kerstin Cuhls, Dr. Anne Stenros, Prof. Adrian Curaj, Ms. Anna Tschaut.
}

and isolated activity. This is still the case in some Member States. The revised Sense-making is more robust and inclusive and considers in particular:

- analysing drivers;

- ensuring vision-building;

- creating alternative scenarios.

'Selecting priorities' and 'implementation' are the last two steps of the foresight process, and are closely linked. They are already well-established at EU and Member State levels. They can be significantly enriched through reinforced strategic intelligence and sense-making processes. These will provide much stronger, genuinely evidence-based analyses of issues and options, and assessments of expected impacts.

It is important to make a clear distinction between formal and informal steps. 'Strategic intelligence' and 'sense-making' are predominantly informal processes of research. However 'selecting priorities' and 'implementation' are formal processes inside the institutions whereby 'intelligent' stakeholders can lend support although formal stakeholders remain in charge. ${ }^{10}$

${ }^{10}$ Ibid. 
Institutionalising foresight in the Commission requires the creation of a foresight 'hub' through which officials coordinate their foresight efforts, including cooperation with the Member States. Important steps have already been taken to set up this 'hub' and it is likely to be operational in the near future. This hub will help advisory groups in their discussions on priorities and directions based on foresight evidence.

Ensuring the quality and integration of 'strategic intelligence' and 'sense-making' will make for better decision-making and more appropriate implementation and monitoring. ${ }^{11}$

\section{The rocky way of foresight in the Commission}

After having outlined the current initiative we will describe in more detail the long-lasting history of foresight inside the European Commission which serves as a background for the current initiative. In the following chapter we will outline the application of foresight within the Commission over time. Its progression to being used as an administrative instrument is characterised by a series of overlapping phases of different forms of application. We may assign these phases to time periods, although these periods only can indicate the most relevant developments.

Over time, foresight has been supported or applied by the Commission in different ways. The Commission has used foresight as an internal advisory capacity by establishing dedicated intelligence units in the institution as the strongest form of foresight application in support of policy decision making. Another approach was funding independent foresight by research grants. In addition, exploratory studies and reports have been commissioned in order to exploit particular results in the interest of the Commission. Another approach was supporting the foresight community in the Member States, co-operating with external institutions and co-ordinating issues in common interest. The phases of interest and of activities undertaken by the European Commission can thus be described as a rise and fall and a rise again of Commission owned foresight.

Exploratory studies and reports (1979-94)

Commissioner Ralf Dahrendorf made what was probably the first attempt at foresight in the Commission in the late 1970s by ordering an internal report, Europe plus 30 (1978). In the end, he did not use the study, as he left the Commission early to teach at the London School of Economics where he eventually became dean.

Nonetheless, Europe plus 30 gave birth to the FAST programme, ${ }^{12}$ run by the Commission's research department at the time, DG XXII. Set up to provide DG XXII with policy

\footnotetext{
$\overline{11} \mathrm{http} / /$ ec.europa.eu/research/innovation-union/pdf/expert-groups/efflareports/effla_pb2_-_how_to_design_a_european_foresight_process. pdfAview $=$ fit\&pagemode $=$ none

${ }^{12}$ FAST - 'forecasting and assessment in science and technology'.
}

advice, FAST was headed from 1979 to 1994 by R. Petrella, during which time it was extended twice. ${ }^{13}$ FAST's mandate and projects had more the flavour of a foresight programme than a science and technology assessment activity. It sought to explore new avenues for research policy and had a strong public profile due to a broad range of publications distributed worldwide.

In the early days of European foresight, there was a request from several parliamentary institutions in the Member States for technology assessment approaches. Consequently, the European Parliament also came up with an initiative in 1987. This was called the Science and Technology Options Assessment (STOA) programme, and was started up by Rolf Linkohr MEP. Under his guidance, STOA grew from a two-year pilot project to an integral part of the European Parliament secretariat's work. In the latest legislature, the chair of STOA was António Correia de Campos, the two vice-chairs were Paul Rübig and Malcolm Harbour; the vice-president of the European Parliament responsible for STOA was Oldřich Vlasák.

The role of STOA is to provide an individual MEP and/or group of MEPs with expert independent assessments of the impact of technology options in the policy sectors that concern the Parliament. These, in particular regard cross-disciplinary and strategic issues.

In 1989, the Commission established a Forward Studies Unit, a small 'think tank' staffed with EU officials and reporting directly to the President, Jacques Delors. This was run along traditional French lines as a cellule de prospective. It was attached to the President's private office and produced a series of forward-looking reflections on policies of a general nature. They are not restricted to science and technology developments and included for example scenarios for Russia or East Asia. Delors' successor, Romano Prodi, converted the cellule into a 'policy advisory group' without foresight activities.

Outsourcing foresight to specific institutions (1993-2003)

When the FAST programme came to an end, the gap was filled by several activities at European level:

- The Institute for Prospective Technological Studies (IPTS) was established in Seville (Spain) in the mid-90s as a part of the Joint Research Centre (JRC). ${ }^{14}$ Its first head was the former director of the Commission's MONITOR research programme, Herbert Allgeier. ${ }^{15}$ IPTS remit

\footnotetext{
${ }^{13}$ The last phase was renewed as a sub-programme under the MONITOR programme. See Eurofutures - The Challenge of Innovation (Butterworth \& Co Publishers Ltd., London 1986) for the results of FAST I. Also, The FASTII Programme (1984-87) - European Futures, prospects and issues in science and technology, summaries of research projects, European Commission, Official Journal (1987).

${ }^{14} \mathrm{JRC}$ is a 'sister' DG to DG RTD.

${ }^{15}$ FAST was part of the MONITOR structure after previously coming under the SAST (technology assessment) programme and prior to being included in the SPEAR (evaluation and research) programme.
} 
was to inform the Commission on new science and technology developments and to carry out its own research. ${ }^{16}$ It ran several successful foresight projects, e.g. on 'futures' and 'ambient intelligence'. ${ }^{17}$

- The European Technology Assessment Network (ETAN) was a pilot action for policy-related research. ETAN came from the Targeted Socio-Economic Research (TSER) programme developed under the Fourth Framework Programme for research and technological development.

- The Science and Technology Policy Options (STRA TA) programme was continued in the Fifth Framework Programme. Activities involved analysis and synthesis on specific issues related to science and technology policies. The programme funded external research rather than supporting a specific analytical unit within the Commission. This was intended to support strategic thinking at academic and national level which would also be of benefit to the Commission to the extent that it could communicate with outside experts.

Return to DG RTD and cooperation with national foresight institutions (2001-2006)

At their March 2000 meeting in Lisbon, the EU's Heads of State and Government agreed on a vision for economic and social development in Europe as a new policy approach. The intention was for the EU to become 'the most competitive and dynamic knowledge-based economy in the world, capable of sustainable economic growth with more and better jobs and greater social cohesion' by 2010 .

The Lisbon Strategy ${ }^{18}$ produced a benchmark for innovation and research in the EU. Europe was perceived as lagging behind its competitors in various areas of science and technology and R\&I policy was seen as a key instrument for remedying this fact. Two years later in Barcelona, the European Council called for increased investment in research to close the gap with Europe's main competitors. Investment was to rise from 1.9 to $3 \%$ of GDP in the EU by 2010, and the proportion funded by business was to rise to two-thirds of the total. Since then, relevant stakeholders have agreed to act on the lines suggested. ${ }^{19}$

Previously and in the same context in the year 2000, the Commission had suggested the development of a European Research Area (ERA). ${ }^{20}$ This was to be a key area for action, identify excellence, strengthen Europe-wide collaboration and establish clearer, more consistent priorities for public research.

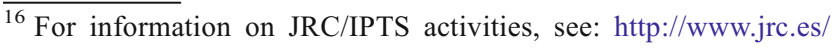
welcome.html

${ }^{17} \mathrm{http}: / /$ is.jrc.ec.europa.eu/pages/TFS/documents/SWAMI_D1_Final_ 001.pdf

${ }^{18} \mathrm{http}: / /$ cordis.europa.eu/programme/rcn/843 en.html

$19 \mathrm{http} / / /$ ec.europa.eu/invest-in-research/pdf/download_en/barcelona european_council.pdf

${ }^{20}$ http://ec.europa.eu/research/era/index_en.htm
}

This would also give European excellence a higher profile in science and research among researchers in other parts of the world.

These political developments formed the basis of the decision to create an in-house foresight unit in the DirectorateGeneral for Research. The idea was to strengthen the foundations of the ERA and ensure consistency in R\&I policies. Work to develop a strong, integrated R\&I area in Europe needed to be guided by a vision on potential growth areas and future perspectives. Forecasting, technology assessment, future studies and other forms of foresight were carried out to identify long term trends and guide decision-making. Foresight was recognised as having the potential to improve R\&I policies and to strengthen the strategic dimension of the ERA.

Over time, many initiatives, activities and institutions had been implemented in the Member States. The Commission preferred to build a platform for exchange to encourage networking and cooperation at European level.

A range of national foresight activities were being conducted across Europe in this period ${ }^{21}$ :

- The UK had the first comprehensive national programme. The first round of this programme took place between 1994 and 1999, covered 15 industry-sector expert panels. The second round ran from 1999 to 2002 and the third round ran from 2002 to $2005^{22}$;

- In France, a wide-ranging exercise for the Ministry of Industry focused on 'key technologies'. In 2003, the National Association for Technical Research (ANRT) launched and coordinated the FUTURIS project, which aimed to stimulate a broad dialogue across society;

- In Germany, the Ministry of Education and Research ran the FUTUR programme. This was an exercise based on new stakeholder participation and aimed at identifying new priorities for science and technology.

The foresight activities provided information through its monitoring and mapping around the world. Results were made available to European foresight actors, ${ }^{23}$ supporting

\footnotetext{
${ }^{21}$ A number of other programmes and activities existed in Member States like Denmark, Sweden, Finland, at regional level like in BadenWurttemberg and Flanders, or outside the Commission like in Korea or at the UNIDO. See: Foresighting Europe Newsletter, http://ec.europa.eu/ research/foresight/10/article_3962_en.htm

${ }^{22}$ Projects concerned: cognitive systems; flood and coastal defence; cyber trust and crime prevention; and exploiting the electromagnetic spectrum.

${ }^{23}$ The European Foresight Monitoring Network (EFMN) project constituted the first element of the European Science and Technology Foresight Knowledge Sharing Platform: it consisted of monitoring Foresight activities relevant to European decision-makers at various levels in the field of research and innovation policy. Moreover, it disseminated the related information by policy briefs to the Foresight community as well as policy-makers.
} 
methodological developments, and mutual learning was supported in the FOR-Learn project.

New institutional preparation (2007-2013)

Foresight activities had no place inside the Commission after 2005. However, support for foresight as an external academic or research activity got funding through the new FP7 programme. This was to build up foresight research capacity in Europe. Despite the above developments, foresight was not taken on board again in the EU until the deep financial crisis that unfolded from 2008.

On 3 March 2010, the Commission proposed a new 10year strategy, Europe $2020,{ }^{24}$ to follow on from the Lisbon Strategy agreed in the year 2000. Seeking to boost the EU economy, the new Europe 2020 strategy aimed at 'smart, sustainable, inclusive growth', with more 'joined-up' national and European policies. Of the Europe 2020 strategy's seven flagship initiatives, it is the Innovation Union initiative ${ }^{25}$ that mostly concerns research and innovation, and which aims to strengthen innovation throughout the Union.

Of the commitments on which the Innovation Union is based, the eighth commitment is most relevant to the area of foresight. It stipulated the creation of a European Forum on Forward-Looking Activities (EFFLA) to bring together existing studies and data. It was to involve public and private stakeholders so as to enhance collective intelligence and help develop better long-term European policies.

EFFLA was set up in 2011 and charged with:

- aggregating the results of outstanding forward-looking activities supported by European or other programmes;

- offering advice on how to use these results for the early identification/understanding of existing/emerging 'grand societal challenges' that could have a significant impact in Europe;

- providing advice and evidence on how these trends could affect European R\&I systems and linking the changes to political processes.

EFFLA's achievements were to 'institutionalise' foresight by mainstreaming it in strategic programming. As a result, foresight is now an integral part of the R\&I policy-making mechanism as described in chapter 3 .

Having successfully fulfilled its remit, EFFLA ceased to exist by April 2014. It was fused with the "Innovation for Growth - i4g" economic expert group and the "European Research and Innovation Area Board (ERIAB)" into a new

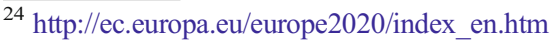

${ }^{25} \mathrm{http}: / /$ ec.europa.eu/research/innovation-union/index_en.cfm

$26 \mathrm{http}: / /$ ec.europa.eu/research/innovation-union/index_en.cfm?pg= expert-groups
}

group, the "Research, Innovation, and Science Policy Expert (RISE)"26 high-level expert group. This new expert group would advise the Commissioner and DG RTD in cooperation with the foresight hub on new priorities of science, research and innovation policy in view of the grand societal challenges.

\section{The grand societal challenges are challenges for foresight}

The European research, technology and innovation programme Horizon 2020 put much explicit focus on resolving prospective global and societal problems. There are three funding areas: academic, industrial, and societal. The area of grand societal challenges received the greatest share of the funds. In the early definition of Horizon 2020 by the Member States, the Swedish Presidency in its Lund Declaration 2009 launched the idea to put central focus on prospective societal problems instead of on industrial lead technology programmes. ${ }^{27}$

The idea was that a challenge-based approach would bring together resources and knowledge across different fields, technologies and disciplines, including social sciences and the humanities. In fact, research activities in Horizon 2020 now bridge research to market with innovation-related activities, such as piloting.

Horizon 2020 will focus funding on the following societal challenges:

- Health, demographic change and wellbeing;

- Food security, sustainable agriculture and forestry, marine and maritime and inland water research, and the bioeconomy;

- Secure, clean and efficient energy;

- Smart, green and integrated transport;

- Climate, environment, resource efficiency and raw materials;

- Europe in a changing world - inclusive, innovative and reflective societies;

- Secure societies - protecting freedom and security of Europe and its citizens.

These challenges mean the following:

"Health, demographic change and wellbeing". Europe already spends nearly $10 \%$ of GDP in this field. The aim is to personalise health and care given the ageing of the European population. The objective is to save the

\footnotetext{
${ }^{27}$ Lund Declaration, "Europe Must Focus on the Grand Challenges of our Time", Swedish EU Presidency, 8 July 2009, Lund, Sweden, http:// www.se2009.eu/polopoly_fs/1.8460!menu/standard/file/lund_ declaration_final_version_9_july.pdf
} 
sustainability and equity of the European health and care system which is under increasing threats.

"Food security, sustainable agriculture and forestry, marine, maritime and inland water and the bio-economy".

This challenge focuses on making the best of our biological resources in a sustainable way. The objective is to contribute to securing sufficient supplies of safe, healthy and high quality food and other bio-based products. This is to be achieved by developing productive, sustainable and resource-efficient primary production systems, fostering related ecosystem services.

"Secure, clean and efficient energy". The EU has agreed on ambitious Energy and Climate targets for 2020 and beyond to reduce greenhouse gas emissions. This is to increase the share of renewable energies and to improve energy efficiency. New technologies and solutions need to compete on cost and reliability with well-established energy systems technologies. Research and innovation are critical to make these new, cleaner, low-carbon, efficient energy sources commercially attractive on the scale needed. They need to be combined with measures facilitating the market uptake of these energy technologies and services.

"Smart, green and integrated transport". The objective of this societal challenge is to achieve a European transport system that is resource-efficient, climate- and environmentally-friendly, safe and seamless. Activities need to aim at resource efficient transport that respects the environment including noise and air pollution. Socioeconomic and behavioural research and forward looking activities for policy making need to support improved policy making.

"Climate, environment, resource efficiency and raw materials". The aim of this societal challenge is to achieve a resource efficient and resilient economy, the protection and sustainable management of natural resources and ecosystems. This is in order to meet the needs of a growing global population within the sustainable limits of the planet's natural resources and eco-systems.

"Europe in a changing world - inclusive, innovative and reflective societies". The aim is to gain a greater understanding of the societal changes in Europe and their impact on social cohesion. The development of innovative societies and policies in Europe need to be fostered through the engagement of citizens, civil society organi- sations, enterprises and users in research and innovation. Another objective is to contribute to an understanding of Europe's intellectual basis, its history and influences.

"Secure societies - protecting freedom and security of Europe and its citizens". This societal challenge aims to protect European citizens, society and economy as well as European assets, infrastructures and services, prosperity, political stability and well-being. It aims to eliminate any malfunction or disruption, either intentional or accidental, that can have detrimental impact with high economic or societal costs. The respect of privacy and civil liberties is the underlying principle.

These seven grand societal challenges are about the future. The challenges will require high solution potential provided by technical and socio-economic research, enriched by foresight activities. The application of solutions is however a political one and less a research or foresight issue. The foresight hub will deal with the assessment of solution potentials and support institutional and administrative decision making in DG RTD. These will influence the decisions for funding allocations and the work programmes for the societal challenges in Horizon 2020.

\section{Conclusions}

The mainstreaming of foresight in DG RTD's policy making mechanism signals that foresight has reached some maturity as a decision support tool for research and innovation policy. It now has to prove that it can be instrumental with decision making on practical R\&I issues. The proof will be in how far the next research and innovation work programme has a greater impact on responding better to society's needs, and in how far it can leave some traces in safeguarding European welfare by research and innovation activities.

Therefore, as foresight research has limits in the real world of policy decision making and policy development, it is to be seen if it can keep its position.

Open Access This article is distributed under the terms of the Creative Commons Attribution License which permits any use, distribution, and reproduction in any medium, provided the original author(s) and the source are credited. 